\title{
Intracaesarean forceps application
}

\author{
Mansi Verma*, Jagruti Keskar, A. N. Bhalerao
}

Department of Obstetrics and Gynecology, B J Medical College, Sassoon General Hospital, Pune, Maharashtra, India

Received: 05 April 2018

Accepted: 30 April 2018

\section{*Correspondence:}

Dr. Mansi Verma,

E-mail: mansiv0504@gmail.com

Copyright: ( ) the author(s), publisher and licensee Medip Academy. This is an open-access article distributed under the terms of the Creative Commons Attribution Non-Commercial License, which permits unrestricted non-commercial use, distribution, and reproduction in any medium, provided the original work is properly cited.

\section{ABSTRACT}

Background: In a time when repeat caesarean deliveries are becoming more frequent, more elective LSCS are being performed and floating vertex are commonly encountered. Sometimes fundal pressure is not adequate, and the physician needs to use instrument (vaccum/forceps) to deliver the head. The objective of the present study is to evaluate maternal and neonatal complications of intracaesarean forceps application

Methods: This was an interventional study which was conducted in OBGY department of Sassoon General Hospital, Pune for 1 year. 75 cases including both emergency and elective sections were included in the study, in which intracaesarean outlet forceps was applied.

Results: Out of 75 cases, maternal complications were seen in 5 cases with uterine incision extensions being the commonest (4\%). Neonatal complications were seen in 3 cases, with minor facial injuries due to pressure of forceps being commonest $(2.6 \%)$.

Conclusions: Intracaesarean forceps when applied skillfully can be effective, fast and safe technique of delivering fetal head in this rising trend of caesarean sections.

Keywords: Intracaesarean, Forceps, Safe caesarean delivery

\section{INTRODUCTION}

There is an upsurge in the incidence of cesarean section rate all over the country with incidence in author's hospital around $20-25 \%$ and the major contributor to this rate is the previous caesarean section group.

This rising trend coupled with a decreasing willingness to allow vaginal birth after cesarean section, has resulted in an expansion of the use of vacuum or forceps assistance to safely extract the fetal head with floating vertex being a common finding in such cases. ${ }^{1,2}$

In an elective cesarean section since the lower uterine segment is not formed completely and not effaced by the process of labour it is difficult to create an adequate incision to enable an uncomplicated delivery. In addition, at the time of an elective repeat cesarean section, the fetal head is normally not engaged in the pelvis which results in complications like deflexed head, sudden change in lie and uterine extensions while delivering the head.

This may require methods like fundal pressure, internal podalic version, or addition of a lateral ("J incision") or midline vertical incision ("Inverted T incision"), all of which can be traumatic for both mother and fetus, and the delay in delivery can increase neonatal morbidity. ${ }^{3}$

This study was performed to know the maternal and neonatal complications of intracaesarean forceps which can be used as a method of delivering floating fetal head.

The objectives of the present study were to evaluate maternal complications of intracaesarean forceps application and to study neonatal complications of intracaesarean forceps application. 


\section{METHODS}

\section{Study Site}

This was an interventional study which was conducted in OBGY department of Sassoon General Hospital, Pune for one-year study.

\section{Inclusion criteria}

- 75 cases including both emergency and elective sections were included in the study, in which intracaesarean outlet (Wrigleys) forceps was applied after taking written informed consent.

\section{Exclusion criteria}

- Patients with severe anemia, malpositions, established chorioamnionitis and presentation other than vertex.

Authors' of the study observed and recorded maternal and neonatal complications arising in these cases.
Procedure performed included taking a transverse lower segment uterine incision, rupturing the membranes and confirming the transverse position of the head. Once the liquor is drained and the head is positioned over the pelvis, first "posterior" blade is introduced gently by guiding it over the dominant hand ensuring nonentrapment of bladder and uterine wall.

This blade is stabilized by the assisting surgeon and then the second "anterior" blade is introduced. To achieve direct access, the surgeon or the assistant inserts a finger into the upper open part of the incision, lifting gently to facilitate sliding the blade into place.

Once the shanks are locked, the deeper blade in the uterus is pulled back to the standard locked position. At this point, the position of the forceps on the head is palpated to confirm that the sagittal suture is oriented transversely between the blades.

Traction is applied, without rotation, along the long axis of the mother. Once the head is delivered blades are removed and rest of the body is delivered as usual.

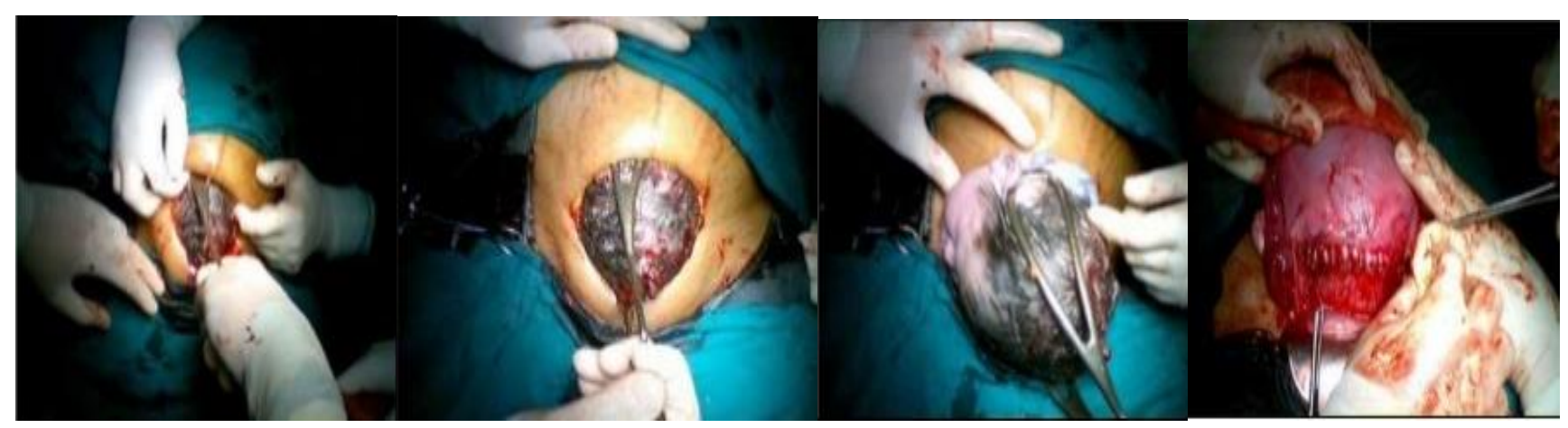

Figure 1: Forceps application at caesarean section.

\section{RESULTS}

In this observational study intracaesarean forceps were applied to emergency as well as elective caesarean sections in 75 cases listed in Table 1.

Table 1: Distribution of cases.

\begin{tabular}{|l|l|l|} 
& Elective & Elmergency \\
\hline No. of cases & 25 & 50 \\
\hline
\end{tabular}

Of these elective as well as emergency cases both floating head as well as engaged head were encountered, and application was done in both the cases.

The average time from incision over the uterus and delivery of fetus after applying forceps blades was 35 seconds. The complications which were observed were grouped as maternal and neonatal listed in Table 2 and Table 3 respectively.

\section{Table 2: List of maternal complications.}

\begin{tabular}{|ll|}
\hline Maternal complications & \\
\hline Uterine incision extensions & $03(4 \%)$ \\
\hline Uterine artery lacerations & $02(2.6 \%)$ \\
\hline J, U or inverted T incision & 00 \\
\hline PPH (traumatic) & 00 \\
\hline Need for interventional surgeries & 00 \\
\hline Broad ligament hematoma & 00 \\
\hline
\end{tabular}

Amongst the neonatal complications, the minor pressure injuries due to blades of forceps were seen which disappeared in 1 or 2 days and only 1 case had minor external eye trauma which resolved in 5 days. 
All neonates were investigated post-delivery using ultrasound through anterior fontanelle in which no injuries were observed.

Table 3: List of neonatal complications.

\begin{tabular}{|ll|}
$\begin{array}{l}\text { Neonatal complications } \\
\text { Minor facial injuries due to pressure of }\end{array}$ & $\begin{array}{l}02 \\
(2.6 \%)\end{array}$ \\
\hline Skull fracture & 00 \\
\hline $\begin{array}{l}\text { Bleeding within the skull (Subgaleal } \\
\text { haemorrhages or intraventricular }\end{array}$ & 00 \\
$\begin{array}{l}\text { Haemorrhage) } \\
\text { Facial palsy }\end{array}$ & 00 \\
\hline Minor external eye trauma & $01(1.3 \%)$ \\
\hline Seizures & 00 \\
\hline
\end{tabular}

\section{DISCUSSION}

Obstetricians all over the world commonly use hand as vectis combined with fundal pressure to deliver fetal head especially non-engaged ones during caesarean sections. At an elective caesarean, the head is often 'free floating' and methods to facilitate delivery include manual delivery utilizing fundal pressure, vacuum extraction, and force. $^{4-6}$

Fundal pressure involves the assistant placing one or two hands on the uterine fundus and exerting downwards force while the obstetrician directs the head towards the uterine incision. Vacuum extraction was first described using a metal cup and then with a soft cup applied directly to the fetal head through the uterine incision. ${ }^{7}$

Introduction of axillary methods like vaccum and forceps have improved the outcome and reduced both maternal and fetal morbidity. ${ }^{4}$ Intracaesarean forceps are useful for cesarean delivery when the fetal head is high in a transverse position, particularly when the operative field provides limited access to the head because of a low transverse incision and maternal obesity.

Successful application of the blades can be accomplished even if large amount of blood and amniotic fluid are in the field. The forceps are not subject to the "pop-off" problems that can occur with vacuum devices. Furthermore, the forceps can be sterilized and reused to avoid adding to the volume of medical waste.

An additional benefit of intracaesarean forceps is that, this instrument has the ability to achieve a secure grip on the fetus by persons of short stature and minimal muscular strength. Without a secure grasp on the head, the small-statured physician may be required to make a larger incision and may require use of a step stool to gain enough mechanical advantage to accomplish delivery.

The only disadvantage is that the person needs to develop skills by adequate training to apply forceps which could otherwise result in disastrous complications. On evaluating the existing literature use of Barton's forceps has been documented for intracaesarean forceps which is specially designed for the same. ${ }^{8}$

In present study author used Wrigley's outlet forceps, for which no previous studies have been conducted. Many studies have proved the efficacy of vaccum being used as tool for delivery e. g Sritippayawan and Chantrapitak, Dimitrov et al compared to manual extraction. ${ }^{9,10}$

One study conducted by Bofill et al compared all the three techniques i. e vaccum, forceps and manual extraction in which no difference was found in the efficacy of either of the instruments but forceps was found to have longer delivery time as compared to vaccum. ${ }^{11}$ From various studies the average time taken by vaccum assisted delivery is 30-60s and in present study average time taken to deliver the fetus from incision on the uterus using forceps was 35s. Hence it depends upon the skills of the surgeon to adequately utilize the benefit provided by the forceps as assisting tool for delivery of fetal head while minimizing its complications.

\section{CONCLUSION}

From the present study author conclude that application of intracaesarean forceps with a skillful and proper technique is safe, fast and effective method of delivering a floating head and to prevent unnecessary maternal and neonatal complications in this rising trend of caesarean section.

\section{Funding: No funding sources \\ Conflict of interest: None declared \\ Ethical approval: Not required}

\section{REFERENCES}

1. Towner D, Castro MA, Eby-Wilkens E, Gilbert WM. Effect of mode of delivery in nulliparous women on neonatal intracranial injury. $\mathrm{N}$ Engl $\mathrm{J}$ Med. 1999;341:1709-14.

2. Bofill JA, Rust OA, Perry KG, Roberts WE, Martin RW, Morrison JC. Operative vaginal delivery: a survey of fellows of ACOG. Obstet Gynecol. 1996;88:1007-10.

3. Okunwobi-Smith Y, Cooke I, MacKenzie IZ. Decision to delivery intervals for assisted vaginal vertex delivery. Br J Obstet Gynaecol. 2000;107: 467-71.

4. De Costa C, Howat P. Caesarean Section: A Manual for Doctors. Australasian Medical Publishing, 2006.

5. Solomen, E. Delivery of the head by Malmstrom vacuum extractor during cesarean section. Obstet Gynecol. 1962;19:201

6. Acosta Sison H, Manilla, P. Forceps for the floating head in low cesarean section. American Journal Obstet Gynecol.1938;35:703-5.

7. Boehm F. Vacuum extraction during caesarean section. Southern Medical J. 1985;78(12):1502. 
8. Barton LG, Caldwell WE, Studdiford WE. The New Obstetric Forceps. Am J Obstet Gynecol. 1928;15:16-26.

9. Sritippayawan S, Chantrapitak W. Assisted delivery of high floating fetal head: a comparison of vacuumassisted delivery and manual extraction. Asian Biomed. 2011;5(5):699-703.

10. Dimitrov A, Pavlova E, Krusteva K, Nikolov A. Caesarean section with vacuum extraction of the head. Akush Ginekol (Sofiia) 2008;47(3):3-6.
11. Bofill JA, Lencki SG, Barhan S, Ezenagu LC. Instrumental delivery of the fetal head at the time of elective repeat cesarean: a randomized pilot study. Am J Perinatol. 2000;17(5):265-9.

Cite this article as: Verma M, Keskar J, Bhalerao AN. Intracaesarean forceps application. Int J Reprod Contracept Obstet Gynecol 2018;7:2415-8. 